\title{
Completely resected stage IIIA non-small cell lung cancer: The significance of primary tumor location and N2 station
}

Yukito Ichinose, $\mathrm{MD}^{\mathrm{a}}$

Harubumi Kato, $\mathrm{MD}^{\mathrm{b}}$

Teruaki Koike, MD ${ }^{\mathrm{C}}$

Ryosuke Tsuchiya, MD ${ }^{d}$

Takehiko Fujisawa, MDe

Nobuyoshi Shimizu, MD

Yoh Watanabe, MDg

Tetsuya Mitsudomi, MD

Masahiro Yoshimura, MD

Masahiro Tsuboi, MD ${ }^{\mathrm{b}}$

The Japan Clinical Oncology Group
From the National Kyushu Cancer Center, Fukuoka, ${ }^{a}$ Tokyo Medical University,

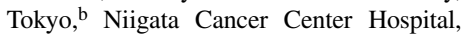
Niigata, ${ }^{c}$ National Cancer Center Hospital, Tokyo, ${ }^{d}$ Chiba University School of Medicine, Chiba, ${ }^{\text {e }}$ Okayama University School of Medicine, Okayama, ${ }^{\mathrm{f}}$ Kanazawa University School of Medicine, Ishikawa, $\mathrm{g}$ Aichi Cancer Center Hospital, Aichi, ${ }^{\mathrm{h}}$ and Hyogo Prefectural Adult Diseases Center, Hyogo, Japan. ${ }^{\mathrm{i}}$

Supported by a Grant-in-Aid (S11-2) for Cancer Research from the Ministry of Health and Welfare, Japan.

Received for publication Feb 1, 2001; revisions requested March 6, 2001; revisions received March 19, 2001; accepted for publication April 12, 2001.

Address for reprints: Yukito Ichinose, MD, Department of Chest Surgery, National Kyushu Cancer Center, 3-1-1, Notame, Minami-ku, Fukuoka 811-1395, Japan.

J Thorac Cardiovasc Surg 2001;122:803-8

Copyright (c) 2001 by The American Association for Thoracic Surgery

0022-5223/2001 \$35.00+ $0 \quad \mathbf{1 2 / 1 / 1 1 6 4 7 3}$

doi:10.1067/mtc.2001.116473
Background: The number of N2 stations (single vs multiple N2 stations) is an important prognostic factor in patients with completely resected stage IIIA-N2 non-small cell lung cancer. However, the significance of both the N2 station(s) actually involved and the primary tumor location remains unclear.

Methods: The database was built with the use of a questionnaire survey on the survival of patients with pathologic stage IIIA-N2 non-small cell lung cancer completely resected between January 1992 and December 1993. The survey was performed by the Japan Clinical Oncology Group as of July 1999. The data include information on the survival and N2 stations of 402 patients.

Results: A frequently metastasized single N2 station was the lower pretracheal station in primary tumors in the right upper lobe, the subaortic station in the left upper lobe, and the subcarinal station in the right middle or lower lobe and the left lower lobe. In multiple $\mathrm{N} 2$ stations, the frequency of metastasis of the $\mathrm{N} 2$ station observed in a single N2 station was as high as $72 \%$ to $89 \%$, and one or two other frequently metastasized stations were added to each group. Regarding the survival of patients with a primary tumor in each lobe except for the left lower lobe, a single N2 station resulted in a significantly better survival than did multiple N2 stations. Furthermore, the overall survivals classified according to each primary site showed a significant difference among the four primary sites $(P=.04)$.

Conclusions: The primary tumors in each lobe showed a prevalence of N2 station(s). The number of $\mathrm{N} 2$ stations is a good prognosticator except in patients with a primary tumor in the left lower lobe. In addition, the site of a primary tumor itself is also considered to influence the survival of the patients.

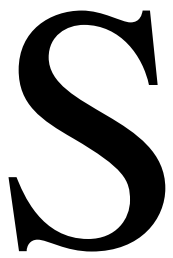

urvival of patients with stage IIIA-N2 disease is known to be variable. Even if the subjects are limited to patients with completely resected pathologic stage IIIA-N2 non-small cell lung cancer (NSCLC), that situation does not change. Therefore, extensive clinical research has been done to elucidate the prognostic factors that are useful for identifying a homogeneous survival subgroup among patients undergoing 
TABLE 1. Patient characteristics $(n=402)$

\begin{tabular}{lr}
\hline Age (y) & \\
Mean (range) & $63(35-82)$ \\
Sex & \\
Male & $287(71 \%)$ \\
Female & $115(29 \%)$ \\
Histologic type & \\
Adenocarcinoma & $268(67 \%)$ \\
Squamous cell carcinoma & $100(25 \%)$ \\
Others & $34(8 \%)$ \\
Pathologic T status & \\
T1 & $126(31 \%)$ \\
T2 & $229(57 \%)$ \\
T3 & $47(12 \%)$ \\
Tumor location & \\
Right upper lobe & $115(29 \%)$ \\
Right middle lobe & $18(4 \%)$ \\
Right lower lobe* & $100(25 \%)$ \\
Left upper lobe & $110(27 \%)$ \\
Left lower lobe & $59(15 \%)$ \\
Operative modality & \\
Pneumonectomy & $46(11 \%)$ \\
Bilobectomy & $33(8 \%)$ \\
Lobectomy & $323(80 \%)$ \\
Postoperative chemotherapy & \\
None & $239(60 \%)$ \\
Done & $163(41 \%)$ \\
Postoperative radiotherapy & \\
None & $341(85 \%)$ \\
Done & $61(15 \%)$ \\
\hline
\end{tabular}

*Two patients had tumor invasion of the right middle lobe.

resection. The prognostic factors ${ }^{1-7}$ identified so far are the pathologic characteristics of the tumor, the extent of the primary tumor, the clinical $\mathrm{N}$ status, the number of $\mathrm{N} 2$ stations, the presence of subcarinal N2 disease, the extracapsular spread in N2 disease, and the extent of the resection. Among these prognostic factors, the number of $\mathrm{N} 2$ stations (single vs multiple) has been recognized as one of the most important. ${ }^{1,6}$ In our previous study using the same subjects as in the present study, the number of $\mathrm{N} 2$ stations was also found to be the most important prognostic factor on the basis of a multivariate analysis. ${ }^{8}$ To our knowledge, however, the site of N2 station(s) actually involved when comparing a single $\mathrm{N} 2$ station with multiple $\mathrm{N} 2$ stations has not been reported. In addition, whether the importance of the number of $\mathrm{N} 2$ stations as a prognostic factor is influenced by the location of the primary tumor remains to be elucidated. In the present study, we therefore attempted to clarify these issues.

\section{Patients and Methods Subjects}

Patients with NSCLC and pathologic stage IIIA-N2 disease completely resected by either a lobectomy or a pneumonectomy from
January 1992 to December 1993 who did not receive preoperative chemotherapy or radiotherapy were the subjects of a questionnaire survey on survival. The survey was conducted by the Lung Cancer Surgical Study Group of the Japan Clinical Oncology Group (JCOG) as of July 1999. The data included information on the survival and the involved N2 station(s) from 406 patients. ${ }^{8}$ All patients underwent computed tomographic scanning of the chest, but mediastinoscopy was not routinely used. Four patients were excluded from the present study because the primary tumor was located in only the main bronchus or the truncus intermedius. The characteristics of all 402 patients are shown in Table 1.

\section{Location of the Mediastinal Lymph Nodes}

The location of the dissected mediastinal lymph nodes was described according to the lymph node map for lung cancer proposed by Naruke and associates ${ }^{7}$ : station 1 , highest mediastinal station; station 2, paratracheal station; station 3, (lower) pretracheal station; station 3a, anterior mediastinal station; station 3p, retrotracheal station; station 4, tracheobronchial station; station 5, subaortic station; station 6, para-aortic (ascending aorta) station; station 7, subcarinal station; station 8, paraesophageal station; and station 9, pulmonary ligament station. The N2 stations were analyzed according to the lobe in which the primary tumor was located.

\section{Survival and Local Recurrence}

The overall survival was defined as the time from the operation until death from any cause. Survival curves were drawn by means of the Kaplan-Meier method and a statistical evaluation of the curves was done by means of a log-rank test.

\section{Results}

\section{General}

The 3- and 5-year survivals of all 402 patients were $42 \%$ (95\% confidence interval [CI]: $37 \%-47 \%$ ) and $31 \%(95 \%$ CI: 26\%-35\%), respectively. The 3- and 5-year survivals of the 209 patients with a single N2 station were $51 \%(95 \%$ CI: $44 \%-58 \%$ ) and $43 \%$ (95\% CI: $36 \%-49 \%$ ), whereas those of the 193 patients with multiple N2 stations were $32 \%(95 \%$ CI: $25 \%-39 \%$ ) and $17 \%$ (95\% CI: $12 \%-22 \%$ ), respectively. The survival of patients with a single N2 station was significantly better than that of patients with multiple N2 stations $(P<.0001)$.

\section{Right Upper Lobe (Table 2 and Figure 1)}

A frequently metastasized N2 station was station 3 in patients with a single $\mathrm{N} 2$ station and stations 1,3 , and 4 in patients with multiple N2 stations. Although the frequency of station 7 involvement was as low as $3 \%$ in patients with a single N2 station, it reached as high as $30 \%$ in patients with multiple $\mathrm{N} 2$ stations.

The 3- and 5-year survivals were 67\% (95\% CI: 55\%-79\%) and $60 \%$ (95\% CI: $48 \%-73 \%$ ) in the 59 patients with a single N2 station, whereas the same survival figures were $28 \%$ (95\% CI: $16 \%-40 \%$ ) and $23 \%$ (95\% CI: $12 \%-35 \%$ ), respectively, in the 56 patients with multiple $\mathrm{N} 2$ stations $(P<.0001)$. 
TABLE 2. Prevalent N2 station(s) in patients with a primary tumor in the right upper lobe

\begin{tabular}{lcc}
\hline & \multicolumn{2}{c}{ No. (\%) } \\
\cline { 2 - 3 } $\begin{array}{l}\text { Station of mediastinal } \\
\text { lymph node }\end{array}$ & $\begin{array}{c}\text { Single N2 station } \\
(\mathbf{n}=\mathbf{5 9})\end{array}$ & $\begin{array}{c}\text { Multiple N2 stations } \\
\text { ( } \mathbf{~ = ~ 5 6 ) ~}\end{array}$ \\
\hline 1 & $5(9 \%)$ & $30(54 \%)^{*}$ \\
2 & $3(5 \%)$ & $24(43 \%)$ \\
3 & $32(54 \%)^{*}$ & $50(89 \%)^{*}$ \\
$3 a$ & $3(5 \%)$ & $10(18 \%)$ \\
$3 p$ & 0 & $2(4 \%)$ \\
4 & $14(23 \%)$ & $36(64 \%)^{*}$ \\
7 & $2(3 \%)$ & $17(30 \%)$ \\
8 & 0 & 0 \\
9 & 0 & $2(4 \%)$ \\
Total & 59 & 171 \\
\hline
\end{tabular}

${ }^{*}$ Frequently metastasized stations.

TABLE 3. Prevalent N2 station(s) in patients with a primary tumor in the right middle or lower lobe

\begin{tabular}{|c|c|c|}
\hline \multirow[b]{2}{*}{$\begin{array}{l}\text { Station of mediastinal } \\
\text { lymph node }\end{array}$} & \multicolumn{2}{|c|}{ No. $(\%)$} \\
\hline & $\begin{array}{l}\text { Single N2 station } \\
\qquad(n=61)\end{array}$ & $\begin{array}{l}\text { Multiple N2 stations } \\
\qquad(\mathrm{n}=57)\end{array}$ \\
\hline 1 & $1(2 \%)$ & $22(39 \%)$ \\
\hline 2 & $4(7 \%)$ & $14(25 \%)$ \\
\hline 3 & $10(16 \%)$ & $39(68 \%)^{*}$ \\
\hline $3 a$ & 0 & $7(12 \%)$ \\
\hline $3 p$ & 0 & $4(7 \%)$ \\
\hline 4 & $3(5 \%)$ & $26(46 \%)$ \\
\hline 7 & $38(62 \%)^{*}$ & $49(86 \%)^{*}$ \\
\hline 8 & $4(7 \%)$ & $12(21 \%)$ \\
\hline 9 & $1(2 \%)$ & $5(9 \%)$ \\
\hline Total & 61 & 178 \\
\hline
\end{tabular}

${ }^{*}$ Frequently metastasized stations.

Right Middle or Lower Lobe (Table 3 and Figure 2)

A frequently metastasized N2 station was station 7 in patients with a single $\mathrm{N} 2$ station and stations 3 and 7 in patients with multiple N2 stations. Although the frequency of station 1 involvement was only $2 \%$ in patients with a single N2 station, that increased to $39 \%$ in those with multiple N2 stations.

The 3- and 5-year survivals were $42 \%$ (95\% CI: $30 \%-55 \%$ ) and $37 \%$ (95\% CI: $25 \%-49 \%$ ) in the 61 patients with a single $\mathrm{N} 2$ station, and they were $33 \%$ (95\% CI: $20 \%-45 \%$ ) and $9 \%$ (95\% CI: $1 \%-16 \%$ ), respectively, in the 57 patients with multiple $\mathrm{N} 2$ stations $(P=.0046)$.

\section{Left Upper Lobe (Table 4 and Figure 3)}

A frequently metastasized $\mathrm{N} 2$ station was station 5 in patients with a single $\mathrm{N} 2$ station and stations 4,5 , and 6 in patients with multiple N2 stations. Although no involvement was observed

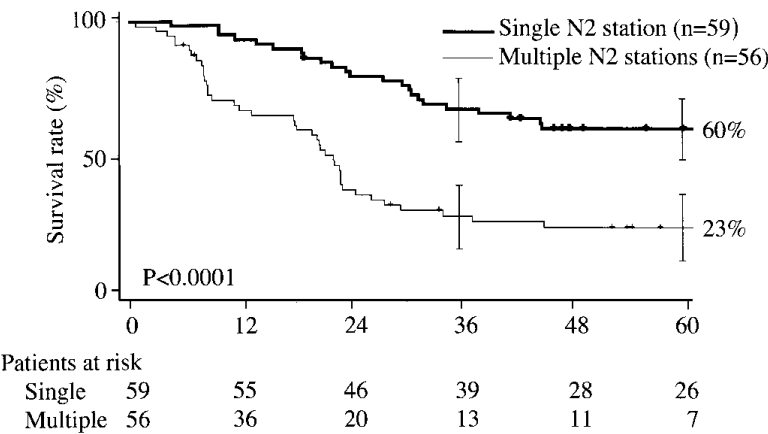

Figure 1. Survival curves of patients with a primary tumor in the right upper lobe. Each bar represents a $95 \%$ confidence interval of the survival.

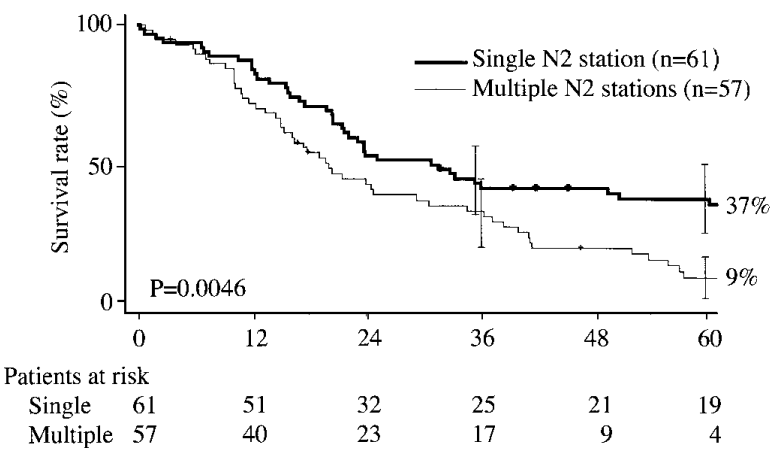

Figure 2. Survival curves of patients with a primary tumor in the right middle or lower lobe. Each bar represents a 95\% confidence interval of the survival.

in the superior mediastinal $\mathrm{N} 2$ stations, including stations 1 to 3 in patients with a single $\mathrm{N} 2$ station, the frequency of involvement in stations 1 plus 2 and station 3 increased to $10 \%$ and $37 \%$ in those with multiple N2 stations, respectively.

The 3- and 5-year survivals were $49 \%$ (95\% CI: $36 \%-62 \%$ ) and $41 \%$ (95\% CI: $28 \%-55 \%$ ) in the 59 patients with a single $\mathrm{N} 2$ station, whereas the same figures were $36 \%$ (95\% CI: $22 \%-49 \%$ ) and $16 \%$ (95\% CI: $5 \%-27 \%)$ in the 51 patients with multiple $\mathrm{N} 2$ stations, respectively $(P=$ 0.0082).

\section{Left Lower Lobe (Table 5 and Figure 4)}

A frequently metastasized N2 station was station 7 in patients with a single $\mathrm{N} 2$ station and stations 5 and 7 in patients with multiple $\mathrm{N} 2$ stations.

The 3- and 5-year survivals were $41 \%$ (95\% CI: $23 \%-59 \%)$ and $22 \%$ (95\% CI: $7 \%-38 \%$ ) in the 30 patients with a single $\mathrm{N} 2$ station, whereas the same survivals were $35 \%$ (95\% CI: $17 \%-54 \%$ ) and $25 \%$ (95\% CI: $7 \%-43 \%$ ) in the 29 patients with multiple N2 stations, respectively $(P=$ $.7361)$. 


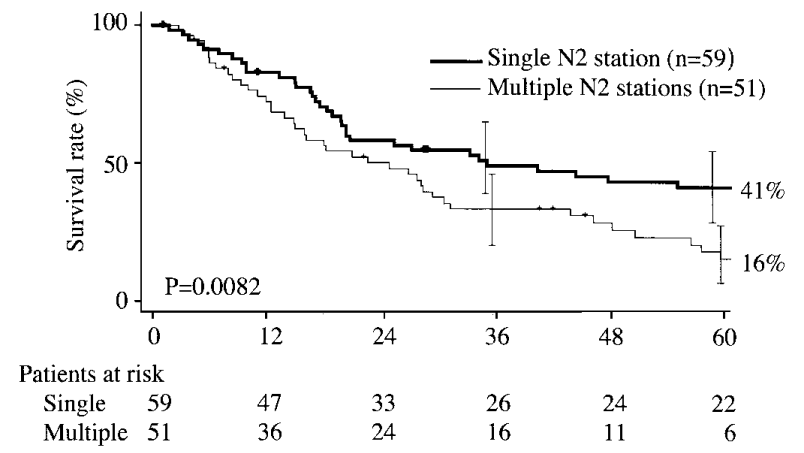

Figure 3. Survival curves of patients with a primary tumor in the left upper lobe. Each bar represents a $95 \%$ confidence interval of the survival.

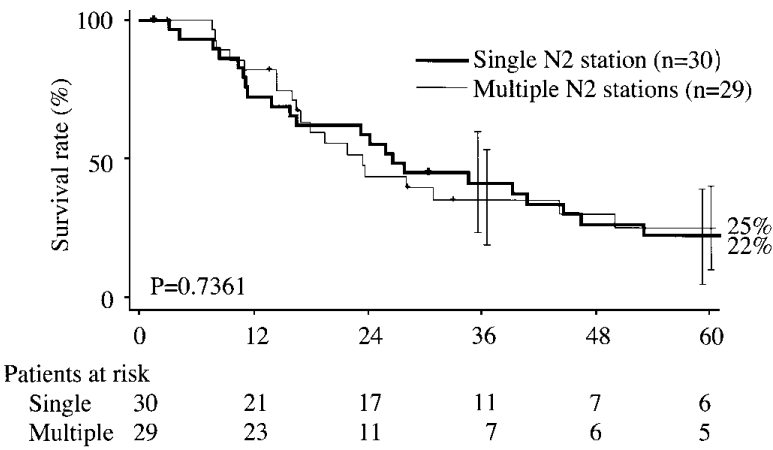

Figure 4. Survival curves of patients with a primary tumor in the left lower lobe. Each bar represents a $95 \%$ confidence interval of the survival.

Comparison of Survival Between Primary Sites (Figure 5)

The 5-year survival was $43 \%$ (95\% CI: $33 \%-52 \%$ ) in patients with a primary tumor in the right upper lobe, $23 \%$ (95\% CI: $16 \%-31 \%$ ) in the right middle or lower lobe, $30 \%$ (95\% CI: $21 \%-39 \%)$ in the left upper lobe, and $23 \%(95 \%$ CI: $12 \%-35 \%$ ) in the left lower lobe. A statistically significantly difference in survival was observed among the four primary sites $(P=.0378)$. The prognosis was not influenced by the side of the primary tumor $(P=.2969)$; the 5 -year survival was 33\% (95\% CI: $26 \%-39 \%$ ) in right-sided tumors and $28 \%$ (95\% CI: $21 \%-35 \%$ ) in left-sided tumors.

\section{Discussion}

The prevalent location of the metastasized mediastinal lymph nodes in patients with stage IIIA-N2 disease has been reported to be the superior mediastinal nodes (especially station 3 or 4) in cancer of the right upper lobe, the subaortic nodes (station 5) in cancer of the left upper lobe, and the subcarinal nodes (station 7) in cancer of both the right middle and lower lobes and the left lower lobe. ${ }^{9,10}$ The most fre-
TABLE 4. Prevalent N2 station(s) in patients with a primary tumor in the left upper lobe

\begin{tabular}{lcc}
\hline & \multicolumn{2}{c}{ No. (\%) } \\
\cline { 2 - 3 } $\begin{array}{l}\text { Station of mediastinal } \\
\text { lymph node }\end{array}$ & $\begin{array}{c}\text { Single N2 station } \\
(\mathbf{n}=\mathbf{5 9})\end{array}$ & $\begin{array}{c}\text { Multiple N2 stations } \\
(\mathbf{n}=\mathbf{5 1})\end{array}$ \\
\hline 1 & 0 & $1(2 \%)$ \\
2 & 0 & $4(8 \%)$ \\
3 & 0 & $19(37 \%)$ \\
$3 a$ & 0 & $6(12 \%)$ \\
$3 p$ & 0 & 0 \\
4 & $7(12 \%)$ & $26(51 \%)^{*}$ \\
5 & $36(61 \%)^{*}$ & $40(78 \%)^{*}$ \\
6 & $11(19 \%)$ & $26(51 \%)^{*}$ \\
7 & $5(9 \%)$ & $13(26 \%)$ \\
8 & 0 & $2(4 \%)$ \\
9 & 0 & $1(2 \%)$ \\
Total & 59 & 138
\end{tabular}

*Frequently metastasized stations.

quently metastasized nodes are considered to be the mediastinal nodes nearest to the primary tumor along the mediastinal lymphatic drainage route. ${ }^{11}$ In patients with multiple N2 stations, however, metastasized nodes located along either an uncommon lymphatic drainage route or the lymphatic drainage route far from the primary tumor are frequently observed, and the present study clearly demonstrated this phenomenon. The metastasized subcarinal nodes observed in $30 \%$ of the patients with a tumor in the right upper lobe and in $26 \%$ of those in the left upper lobe, and the metastasized subaortic nodes in $59 \%$ of those in the left lower lobe, represent the former case. The metastasized highest mediastinal nodes (station 1) observed in $54 \%$ of the patients with tumor in the right upper lobe and the metastasized lower pretracheal nodes (station 3) in 68\% of those in the right middle or lower lobe represent the nodal involvement along the lymphatic drainage route far from the primary tumor.

The relatively high frequency of skip mediastinal lymph node metastasis, in which the affected lymph nodes were not in the prevalent location for metastasis, in patients with a single N2 station was an interesting finding in this study. In particular, in cancer of the right middle or lower lobe and of the left lower lobe, $30 \%$ of the patients with a single N2 station had metastasis to abnormal sites: to the right-sided superior mediastinal nodes, including stations 1 to 4 , and to the left-sided nodes, including stations 4 to 6 , respectively. Takizawa, ${ }^{9}$ Riquet, ${ }^{12}$ and their associates reported that among the dissected lymph nodes that were determined to have metastasis on the basis of a postoperative pathologic examination, $68 \%$ and $20 \%$ of these nodes, respectively, were judged to have no metastasis according to intraoperative macroscopic examinations. On the basis of the above 
TABLE 5. Prevalent N2 station(s) in patients with a primary tumor in the left lower lobe

\begin{tabular}{lcc}
\hline & \multicolumn{2}{c}{ No. (\%) } \\
\cline { 2 - 3 } $\begin{array}{l}\text { Station of mediastinal } \\
\text { lymph node }\end{array}$ & $\begin{array}{c}\text { Single N2 station } \\
(\mathbf{n}=\mathbf{3 0})\end{array}$ & $\begin{array}{c}\text { Multiple N2 stations } \\
\text { (n = 29) }\end{array}$ \\
\hline 1 & 0 & $2(7 \%)$ \\
2 & 0 & $2(7 \%)$ \\
3 & 0 & $3(10 \%)$ \\
$3 a$ & 0 & $1(3 \%)$ \\
$3 p$ & 0 & 0 \\
4 & $5(17 \%)$ & $14(48 \%)$ \\
5 & $3(10 \%)$ & $17(59 \%)^{*}$ \\
6 & $1(3 \%)$ & $5(17 \%)$ \\
7 & $17(57 \%)^{*}$ & $21(72 \%)^{*}$ \\
8 & $3(10 \%)$ & $7(24 \%)$ \\
9 & $1(3 \%)$ & $5(17 \%)$ \\
Total & 30 & 77 \\
\hline
\end{tabular}

${ }^{*}$ Frequently metastasized stations.

findings and our present data, a systemic nodal dissection is thus thought to be necessary, not only to obtain a precise staging of the disease but also to eradicate the intrathoracic disease.

The present study demonstrated that the number of $\mathrm{N} 2$ stations (single vs multiple N2 stations) is an important prognostic factor in patients with a primary tumor in the right lung and the left upper lobe but not in the left lower lobe. However, at the same time, the prognosis of patients with a single $\mathrm{N} 2$ and multiple $\mathrm{N} 2$ stations was demonstrated to be influenced by the location of the primary tumor. Among patients with a primary tumor in the right upper lobe, the 5-year survival was $60 \%$ in patients with a single $\mathrm{N} 2$ station and $23 \%$ in those with multiple N2 stations. On the other hand, the 5-year survival among patients with a primary tumor in the right middle or lower lobe was $37 \%$ in patients with a single N2 station and $9 \%$ in those with multiple $\mathrm{N} 2$ stations.

To our knowledge, whether the location of the primary tumor in patients with completely resected pathologic stage IIIA-N2 NSCLC influences survival has yet to be elucidated. In the present study, the prognosis of patients was significantly different depending on which of the four primary sites was affected. The 5-year survival was $23 \%$ in patients with a primary tumor in either the right middle and lower lobes or the left lower lobe. This figure was worse than the $43 \%$ survival in right upper lobe tumors or the $30 \%$ survival in left upper lobe tumors. These observations indicate that lung cancer in the lower lobe with $\mathrm{N} 2$ disease may be more advanced than cancer in the upper lobe with $\mathrm{N} 2$ disease.

Subcarinal lymph node metastasis, which is most frequently observed among the metastasized mediastinal

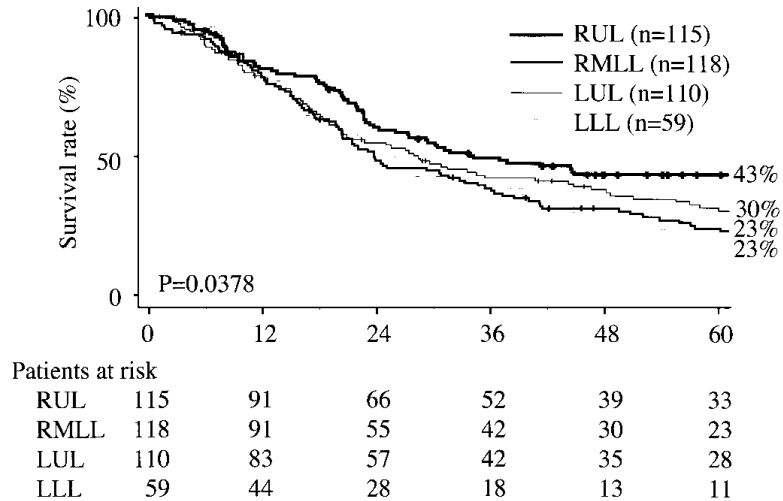

Figure 5. Survival curves of the patients classified by the primary tumor site. $R U L$, Right upper lobe; $R M L L$, right middle and lower lobes; $L U L$, left upper lobe; $L L L$, left lower lobe.

lymph nodes of patients with cancer in the lower lobe including the middle lobe, is thus reported to adversely influence survival. ${ }^{7}, 13,14$ However, these poor results may reflect the poor prognosis of patients with cancer in the lower lobe. In fact, the survival of patients with a single N2 station whose primary tumor was located in the middle or lower lobes in the present study was not influenced by the presence or absence of the subcarinal lymph node metastasis: the 5-year survival of cancer in the right middle or lower lobe was 36\% (95\% CI: 20\%-51\%) in the 38 patients with subcarinal nodal involvement as a single $\mathrm{N} 2$ station and $34 \%$ (95\% CI: $14 \%-53 \%$ ) in the 23 patients with the nodal involvement of the other sites as a single N2 station ( $P=$ .3738; data not shown in the "Results"). In patients with cancer in the left lower lobe, the 5-year survival was $22 \%$ (95\% CI: $1 \%-43 \%$ ) in the 17 patients with the subcarinal nodal involvement as a single N2 station and 23\% (95\% CI: $0 \%-46 \%)$ in the 13 patients with the nodal involvement of the other sites as a single N2 station $(P=.9064$; data not shown in the "Results").

In conclusion, the number of $\mathrm{N} 2$ stations (single N2 vs multiple N2 stations) and the location of the primary tumor was found to influence the survival of patients with completely resected stage IIIA-N2 NSCLC. Therefore, these factors should be included as a stratified factor in a prospective clinical trial of such patients.

We thank Masanori Shimoyama, MD, chairperson of the Japan Clinical Oncology Group; Nagahiro Saijo, MD, chairperson of the Lung Cancer Study Group of the Japan Clinical Oncology Group for his support in this study; Satoru Inutsuka, MD, of Kyushu University for his help with the statistical analysis; Brian Quinn for his critical review; and Yumiko Oshima for her help in preparing the manuscript.

\section{References}

1. Martini N, Flehinger B. The role of surgery in N2 lung cancer. Surg Clin North Am. 1987;67:1037-49. 
2. Watanabe Y, Shimizu J, Oda M, Hayashi Y, Watanabe S, Tatsuzawa Y, et al. Aggressive surgical intervention in N2 non-small cell lung cancer of the lung. Ann Thorac Surg. 1991;51:253-61.

3. Goldstraw P, Mannam G, Kaplan D, Michael P. Surgical management of non-small cell lung cancer with ipsilateral mediastinal node metastasis (N2 disease). J Thorac Cardiovasc Surg. 1994;107:19-28.

4. Vansteenkiste JF, De Leyn PR, Deneffe GJ, Stalpaert G, Nackaerts KL, Lerut TE, et al. Survival and prognostic factors in resected N2 non-small cell lung cancer: a study of 140 cases. The Leuven Lung Cancer Group. Ann Thorac Surg. 1997;63:1441-50.

5. Suzuki K, Nagai K, Yoshida J, Nishimura M, Takahashi K, Nishiwaki Y. The prognosis of surgically resected N2 non-small cell lung cancer: the importance of clinical N status. J Thorac Cardiovasc Surg. 1999;118:145-53.

6. Andre F, Grunenwald D, Pignon J-P, Dujon A, Pujol JL, Brichon PY, et al. Survival of patients with resected N2 non-small-cell lung cancer: evidence for a subclassification and implications. J Clin Oncol. 2000;18:2981-9.

7. Naruke T, Suemasu K, Ishikawa S. Lymph node mapping and curability at various levels of metastasis in resected lung cancer. $J$ Thorac Cardiovasc Surg. 1978;76:832-9.

8. Ichinose Y, Kato H, Koike T, Tsuchiya R, Fujisawa T, Shimizu N, et al. Overall survival and local recurrence of 406 completely resected stage IIIa-N2 non-small cell lung cancer patients: questionnaire survey of the Japan Clinical Oncology Group to plan for clinical trials. Lung Cancer. In press.

9. Takizawa T, Terashima M, Akamatsu H, Kurita Y, Yokoyama A. Mediastinal lymph node metastasis in patients with clinical stage I peripheral non-small-cell lung cancer. J Thorac Cardiovasc Surg. 1997;113:248-52.

10. Asanuma $H$, Nakayama $H$, Kondo $H$, Tsuchiya $R$, Naruke T. Lobespecific extent of systematic lymph node dissection for non-small cell lung carcinomas according to a retrospective study of metastasis and prognosis. J Thorac Cardiovasc Surg. 1999;117:1102-11.

11. Hata E, Hayakawa K, Miyamoto H, Hayashida R. Rationale for extended lymphadenectomy for lung cancer. Theor Surg. 1990;5:1925.

12. Riquet M, Manac'h D, Saab M, Le Pimpec-Barthes F, Dujon A,
Debesse B. Factors determining survival in resected N2 lung cancer. Eur J Cardiothorac Surg. 1995;9:300-4.

13. Pearson F, DeLarue N, Ilves R, Todd T, Cooper J. Significance of positive superior mediastinal nodes identified at mediastinoscopy in patients with resectable cancer of the lung. J Thorac Cardiovasc Surg. 1982;83:1-11.

14. Regnard J, Magdeleinat P, Azoulay D, Dartevelle P, Deneuville M, Rojas-Miranda A, et al. Results of resection for bronchogenic carcinoma with mediastinal lymph node metastases in selected patients. Eur J Cardiothorac Surg. 1991;5:583-7.

\section{Appendix}

\section{Additional Participating Institutions and Principal Investigators}

Nagasaki University School of Medicine (Hiroyoshi Ayabe, MD) Osaka Prefectural Adult Disease Center (Ken Kodama, MD)

Iwaki Kyoritsu Hospital (Yoshio Yamane, MD)

Tochigi Cancer Center (Kohei Yokoi, MD)

Tohoku University School of Medicine (Shigefumi Fujimura, MD)

Saitama Cancer Center (Mitsunobu Yamamoto, MD)

Keio University School of Medicine (Koichi Kobayashi, MD)

National Okinawa Hospital (Keiichiro Gengka, MD)

Gunma Cancer Center (Sachio Shimizu, MD)

National Cancer Center, East (Kanji Nagai, MD)

Kumamoto Central Hospital (Noboru Fujino, MD)

Cancer Institute (Ken Nakagawa, MD)

Shikoku Cancer Center (Masao Nakata, MD)

National Kure Hospital (Kenji Nakamura, MD)

Takatsuki Red-Cross Hospital (Wataru Chiba, MD)

Ibaragi Cancer Center (Ryuta Amamiya, MD)

Osaka City General Hospital (Hirohito Tada, MD)

Kyorin University School of Medicine (Tomoyuki Goya, MD) 